\title{
On the Meaning of Personal Names: A View From Cognitive Psychology
}

\author{
Tim Brennen \\ University of Tromsø, Norway
}

\begin{abstract}
I contrast two different answers to the question of how much meaning personal names carry. A review of the cognitive psychology of proper name memory suggests that people's names are typically not processed for meaning. Contradictorily, there is ample empirical and anecdotal evidence that personal names do carry meaning. A solution to this paradox is proposed through two considerations. First, I suggest that a name's meaning carries most force when one is first exposed to it; thereafter the meaning becomes progressively less important. Second, there is variation in how much a person's name means to its bearer. Although the names of some people clearly influence behavior in some ways, personal names do not carry the same degree of meaning for everyone. By considering the psychological concept of identity, I claim that one's name is destined, for most people, to be little more than a label.
\end{abstract}

There are essentially two (apparently contradictory) views of the meaning of one's name for one's identity; here I will reconcile the two. In cognitive psychology there is an empirical database and several theoretical strands which suggest that one's name plays no (or very little) role in constructing, developing, and maintaining one's identity. This is in stark contrast to the less structured and often unstated-but nevertheless widespread-belief that exists regarding the central importance of one's name for one's identity.

\section{Memory for Personal Names}

A common intuition is that people's names are difficult to remember; in particular, they appear to be more easily forgotten than information identifying a person. This intuition is supported by empirical evidence from studies of the use of names in daily life, from the cognitive laboratory, and from neuropsychology. The empirical reality that names are especially difficult to recall has been explained in several

Names 48.2 (June 2000):139-146

ISSN:0027-7738

(C) 2000 by The American Name Society 
ways. Before summarizing some of these, however, I will describe one laboratory study that presents a challenge for any explanation proposed thus far. McWeeny et al. (1987) asked judges to associate each of 16 unfamiliar faces with an occupation and a surname. As each face was presented sentences such as these were read: "This is Mr. Porter; he is a cook." "This is a politician; she is called Mrs. Diamond." Then the faces were presented alone and the judges were asked to recall the correct occupations and the correct names. Despite the fact that the instructions gave equal importance to names and to occupations, on the great majority of trials where only one piece of information was recalled, it was the occupation that was remembered and not the name; it was rare for judges to recall the name alone but much more common for the occupation to be recalled alone. This result is even more compelling (and also more difficult to explain) since for each subject half of the occupations and half of the names were what McWeeny et al. (1987) called "ambiguous;" that is, labels that, in English, occur as both occupations and as surnames. Notably, the disadvantage of memory for names was also true of the ambiguous labels, suggesting that a given word is easier to learn and to recall when it refers to an occupation than when it is a surname.

The explanation offered by McWeeny et al. (1987) is that surname labels are processed in a less elaborate manner than are occupation labels; when one attempts to learn, for instance, gardener, a profession, one can draw upon the variety of associations, visual images, facts and stereotypes which one has for that term. On the other hand, when one learns Gardener, a surname, no such processing will occur because one has little (if indeed any) information about the category of people who share the surname Gardener. Cohen's (1990) explanation claims that proper names are hard to recall because they are not integrated with the rest of a person's semantic system and is thus similar to the explanation of McWeeny et al. (1987), but it is also more general in that it extends to given names as well as surnames. This position can be summarized by saying that proper names are meaningless and that they are processed rather like nonsense words.

Brennen (1993) proposed a different explanation, one that began with the observation that adults continue to learn new exemplars of 
surnames throughout their lives, where with other word classes few new words are learned after adolescence. Surnames that are recent acquisitions for many people, globally, include Barak and Yeltsin, new exemplars of first names may include Keanu and Slobodan. The set of names, given names and surnames, is thus not closed but remains open all one's life, in contrast to other word classes, such as the names of pieces of furniture or of foods. Other categories of proper names, such as the names of countries, also produce exemplars new to many people (such as Kosovo), but hardly at a rate as high as that of people's surnames.

One consequence of this constant adding of new surnames is that surnames are harder to guess on the basis of partial information. This means, for example, that it is harder confidently to complete a partial surname than it is to complete a partial common noun. To see how much more difficult it is to complete surnames, try the following thought experiments:

I am thinking of the name of a country. You must try to guess which one. The clue is that it completes the following: "Denm

I am thinking about a kind of metal, one that would complete the following: "ste_.."

Most people would answer "Denmark" and "steel," respectively and relatively unproblematically. Now try to complete the same incomplete forms with surnames. My prediction is that the task is harder when completing surnames than when completing other types of names, and furthermore that even if you responded with Denmark and steel, you would be less confident that they were the correct answers than if you were looking for the name of a country and the name of a metal. This is true, I would claim, even if Denmark and Steel were the only surnames you knew that completed those particular patterns, because our lifelong experience with surnames has taught us that new ones appear constantly, so we accept intuitively the possibility that there could be a person called, for instance, Denman or Denmickle, even though we have never encountered the names before, whereas it seems quite ludicrous to think that there may be a country one has never heard of beginning with "Denm__." The extra difficulty encountered when completing 
people's names on the basis of partial information is what causes them to be difficult to recall.

The cognitive psychology of proper name memory, then, shows us that personal names are difficult to learn and difficult to recall, both in everyday life and in laboratory settings (see Valentine, Brennen and Brédart [1996] for a review). Proper names are phonologically anarchic (Brennen 1993), not well-integrated semantically (Cohen 1990), and typically, they are not processed for meaning (McWeeny et al. 1987).

\section{Personal Names are Meaningful}

There is, however, a great deal of evidence from everyday life and in the scholarly literature which supports the notion that personal names are meaningful. While it cannot be claimed that names are invariably reliable cues to information about their bearers, the opposite view that no reliable information can be gained from a person's name is equally untenable, since, for instance in western countries, we can rather reliably determine the gender of the bearer of most given names. There are exceptions, of course; Leslie and Kim are of indeterminate gender in most English-speaking countries. One's name is often a valuable clue to one's nationality or mother tongue, although again there are exceptions. Social class, too, may also be hinted at by a name. In England Lee and Wayne call up lower class images, although the same is true of Harry, and yet the person who is third in line to the British throne bears that name. Additionally, some names carry connotations of age, such as Gertrude in England and Olga in Norway, although there are younger people with these names as well.

The connotations that names carry has been richly documented by a variety of researchers and is remarkably consistent among judges, e.g., Kasof (1993), Lawson and Roeder (1986) and Mehrabian (1997). It should be noted, however, that this type of meaning, although consensual, is also weak and probabilistic, rather than compelling and incontrovertible. Many would agree, for example, that Francesca is a "pretty" name, and that Rupert is a "posh" name. But realistic judgements on the basis of name information are difficult. If Francesca is a pilot, 30 years old and Danish, one is able to infer more correct things about her from any one of these facts than from her name alone, thus supporting the view from cognitive psychology that names have rather impoverished semantics. 
Solution of the Paradox

How can we reconcile these two apparently incompatible positions? I propose two ways that will lead to a solution.

\section{First Impression Versus Repeated Exposures}

The first time one hears a name one may well process it semantically, but, I suggest, less and less such processing for meaning is done with each subsequent exposure to the name.

Consider the phenomenon that the first time one hears a personal name it often has humorous connotations. Over time, however, that name loses its ability to raise even a smile. The phenomenon is frequent for foreign names, when, for example, English speakers learn that some Norwegians are actually called Bent or that Andrea is a boy's name in Italy. The urge to smile at the holder of the name because of the name fades and after repeated exposures the name is no longer processed semantically. Similarly, the first time one hears about Eliza Doolittle in George Bernard Shaw's Pygmalion, one may be struck by the appropriateness of her family name, whereas over time the impact of the name fades. The same phenomenon may be seen in J.B. Priestley's "An Inspector Calls," which features the elusive and mysterious detective named Goole.

Thus, I would claim that the anecdotal evidence is correct in that we do tend to process the meaning of names the first few times we encounter them, but in the long run, as suggested by the cognitive literature, we process names almost entirely free of meaning.

We can also ask whether a previously familiar name associated with a different person affects one's first impressions of that second person. Typically, in studies of the connotations of names, judges give ratings of names in the absence of any accompanying information. Steele and Southwick (1989) asked one group of judges to rate a person on five dimensions (good/bad, sincere/insincere, etc.) from a name alone, and another group to rate a person along the same dimensions from the name plus a (neutral) photograph. Previous research had determined that some names, such as Gregory, were consistently rated "good," while others, such as Edmund, were rated "bad." There was a large effect of "namegoodness" when the judgement occurred without a photograph, but no effect in the presence of a photograph. Thus, in many studies of the connotations of names judges are put in precisely the situations that will 


\section{Names 48.2 (June 2000)}

tend to maximize the impact of the connotative meanings of the names. This impact, however, is susceptible to supplementary information, even when that information is as simple as an unobtrusive photograph.

\section{Variation in Personal Name Meaning}

The second way to reconcile the paradox of the meaning of names comes from a realization that for some people their names are very meaningful and can play a guiding role in behavior, while for others, their names are merely labels.

We need to draw a distinction between the meaning of a name for the bearer and its meaning for others. The meaning of personal names for others refers to connotations such as those mentioned above. This meaning is external, as names are perceived by the outside world. The internal meaning of a name is another matter. Internal meaning here refers to what the name means to the bearer, and this obviously varies considerably from person to person. One person called Matthew can be strongly attached to this name, perhaps for religious reasons, whereas another person called Matthew may feel little investment in the name. It is beyond debate that some people have high name attachment, so that we can answer in the affirmative as to whether a name can influence one's identity. For others, however, their names are simply labels, in which very little emotion or meaning is invested. Not surprisingly, the "name-stories" of the former, who feel high name attachment are overrepresented in our anecdotes because the latter do not have such stories to tell. This fact alone leads one easily to overestimate the true level of meaning which names carry, and one should not be misled into thinking that names always play a large part in one's identity.

The concept of identity is studied from at least five perspectives in the psychological literature: historical, structural, sociocultural, narrative and psychosocial (Kroger, 2000). Thus any particular definition of identity will be condemned by most theoreticians. This fact notwithstanding, identity may eclectically be defined as a relatively stable self-picture, which consists of the opinions, attitudes, habits, and beliefs that last relatively unchanged over long periods of time. Identity, then, is thus a wholly personalized, amorphous narrative about who one is and what one stands for. It is multifaceted and the particular aspect that is emphasized at any moment depends sensitively on the pertaining 
situation. While I would not expect any identity theorist fully to embrace this definition, the basic elements of it are shared by most current theories. Identity is intimately personal and "fuzzy," and each person's identity is a complex web of many different strands. It is in this context that the impact of one's name on one's identity should be seen. Identity is a fluid and complex constellation, and one's name is one of many elements constituting that identity. It is of course possible for people to act as a function of their names, but this does not mean that the name is necessarily such an important element.

Consider a person who is Norwegian and who is also a plumber who plays the guitar, who is called Halvard, who climbs mountains, and who is married. This person's identity would consist of a mixture of all these elements and others, which are more or less prominent in different contexts, such as being at home, at work, with his in-laws, with friends or being abroad. His name is of little relevance to his identity in most of these situations. I would go further, to say that there are very few times when it is possible for his name to have substantial influence on his identity. One such situation, perhaps, is when meeting someone for the first time who, by chance, shares the same name; they might have a temporary bond on this basis, but if that is all they have in common, the acquaintance will be rather brief. There is no real-life replica of the experimental situation where a person's name and gender is all one knows about a person.

After the first few encounters with people's names we stop processing them for meaning. For some people their given names are important identity-forming, behavior-guiding elements, which can overtly or covertly guide their life choices. One must, however, take care not to generalize from the compelling anecdotes about a name's influence to the belief that names are necessarily intimately bound up with one's identity. For many people, names are merely labels.

\section{Note}

I would like to thank Gulbrand Alhaug, Jane Kroger, and Bruno Laeng, the participants in the Evaluation Seminar, Trondheim, May 1999, and the students from the Department of Psychology and from the Faculty of Humanities who attended the course on Proper Names and Identity, at the University of Tromsø, 1997. The School of Psychology, University of Exeter, provided excellent facilities during the revision of the manuscript. 


\section{References}

Brennen, Tim. 1993. "The Difficulty with Recalling People's Names: The Plausible Phonology Hypothesis." Memory 1:409-31.

Cohen, Gillian. 1990. "Why is it difficult to put names to faces?" British Journal of Psychology 81:287-97.

Kasof, Joseph. 1993. "Sex Bias in the Naming of Stimulus Persons." Psychological Bulletin 113:140-63.

Kroger, Jane. 2000. Identity Development: Adolescence Through Adulthood. Newbury Park, CA: Sage.

Lawson, Edwin D. and Lynn M. Roeder. 1986. "Women's Full First Names, Short Names, and Affectionate Names: a Semantic Differential Analysis." Names 34:175-84.

McWeeny, Kathryn, Andy Young, Dennis Hay, and Andy Ellis. 1987. "Putting names to faces." British Journal of Psychology 78:143-49. Mehrabian, Albert. 1997. "Impressions Created by Given Names." Names 45:19-33.

Steele, Kenneth M. and Laura E. Southwick. 1989. "First Names and First Impressions: A Fragile Relationship." Sex Roles 21:517-23. Valentine, Tim, Tim Brennen, and Serge Brédart. 1996. The Cognitive Psychology of Proper Names: The Importance of Being Ernest. London: Routledge. 